\title{
Explaining Social Exchanges in Information-Based Online Communities
}

\author{
Sabine Benoit \\ Professor of Marketing \\ Surrey Business School \\ University of Surrey \\ Guildford, UK \\ Phone: +44 1483683048 \\ s.benoit@surrey.ac.uk
}

Nicola Bilstein

Assistant Professor of Service Management

Ingolstadt School of Management

Catholic University of Eichstätt-Ingolstadt

Auf der Schanz 49

85051 Ingolstadt, Germany

Phone +49 84193721861

Email: nicola.bilstein@ku.de

Jens Hogreve

Professor and Chair of Service Management Ingolstadt School of Management

Catholic University of Eichstätt-Ingolstadt

Auf der Schanz 49

85051 Ingolstadt, Germany

Phone +49 84193721861

Email: jens.hogreve@ku.de

\section{Christina Sichtmann}

Department of Business Administration

University of Vienna

Oskar-Morgensternplatz 1

1090 Vienna, Austria

Phone: +43 1427738032

E-Mail: christina.sichtmann@univie.ac.at 


\title{
Explaining Social Exchanges in Information-Based Online Communities (IBOC)
}

\begin{abstract}
Purpose: Information-based online communities (IBOCs, like LinkedIn or Facebook) provide platforms for members to exchange information. Because member participation is vital for IBOCs, this research aims to identify and validate factors that drive member participation.

Methodology: With reference to social exchange theory we developed a model of antecedents of participation in IBOCs that was tested with survey data using PLS. Because some of our results contradicted the theory, we examined those results in a mainly qualitative study with online community providers. These experts offered explanations that inform our discussion and managerial implications.
\end{abstract}

Findings: Role clarity, provider's responsiveness, and enjoyment all influence member participation. Contrary to theory, the cooperation of other members affects member participation negatively while a member's ability shows no effect.

Practical implications: This research has several implications for IBOC providers. Because ability does not affect participation directly, providers do not need to worry about lacking ability and can effectively target all potential members. The importance of provider responsiveness signals that IBOC providers should proactively monitor members' compliance with social norms to lower the social risk for members. The impact of community specific knowledge and enjoyment on participation puts emphasis on careful community design and the thoughtful implementation of new features that might enhance enjoyment, but reduce role clarity. 
Originality/value: Whereas most of the participation literature focuses on a dyadic relationship, our research investigates the triadic relationship in which the provider is only an enabler of exchange. Furthermore, we bring together two streams of the literature: the participation literature, which tends to focus on offline participation; and the online community literature, which has not yet investigated participation. This is also the first paper to investigate nonlinear effects on participation.

Keywords: participation, information-based online communities, services marketing. 


\section{Introduction}

Information-based online communities (IBOCs) empower customers, as members, to connect and cultivate relationships (Dholakia et al., 2004; Wiertz and de Ruyter, 2007). A wellknown example of an IBOC is LinkedIn, which enables professionals to connect, find jobs or providers, discover new business opportunities, and ask or answer questions. Facebook offers an equivalent social exchange for more leisure related information.

OCs in general and IBOCs in particular influence consumer behavior significantly. Up to $80 \%$ of U.S. and U.K. consumers report that the information they gather from social media platforms is a primary prompt for their activities (Forbes, 2012). More than $12 \%$ of consumers make purchases after receiving encouragement through Facebook (Khazan, 2011). Participating in IBOCs, defined as exchanging information via online platforms, has become an important element in the everyday lives of consumers, and the power of IBOCs to affect consumer behavior is likely to continue increasing (Crowd Companies, 2014). Thus OC providers must engage their customers to enhance their own strategic performance (Brodie et al. 2011).

Stimulating participation requires knowing its key drivers (Bendapudi and Leone, 2003; Gallan et al., 2013; Xue and Harker, 2002), and encouraging consistent participation over time proves especially challenging (Ren et al., 2012). Although participation is not a new phenomenon and links to other constructs like customer integration (e.g. Moeller 2008) and customer engagement (e.g. van Doorn et al., 2010), pertinent empirical research is still needed to clarify the antecedents of this behavior in general (Guo et al., 2013) and in the particular context of online encounters and online communities (Kunz and Hogreve, 2011; Munzel and Kunz, 2014). 
Against this background, our research seeks to identify and validate factors that drive member participation in IBOCs using two empirical studies. This article offers two main contributions to the literature on participation and online communities as well as guidance for practitioners as a third contribution. First, most participation research addresses the dyadic relationship between customers and service providers (e.g., Bendapudi and Leone, 2003; Chan et al., 2010), whereas we acknowledge that IBOC members both offer and demand information while the provider enables participation by providing the platform (Bakos and Katsamakas, 2008; Cho and Menor, 2010). Therefore, following Hammedi et al. (2015) we investigate participation in the triadic relations of the focal member, fellow community members, and the community provider to identify and validate the determinants of participation.

Second, our methodology involving expert opinions in the second study, to reflect on our results from Study 1, demonstrates a useful and feasible approach for academics to reach a managerial audience and thereby increase the relevance and impact of their research. Study 1 tests a model derived from theory and the existing academic literature. Because we found some unexpected effects, we explore the results from Study 1 with experts who actually run and manage an online community (Study 2). Study 2 tests our results against their real-world experiences, and we propose explanations for the mismatch between theory and reality.

Third, our research yields clearer managerial guidance for how an "organization [should] create, interact with and manage customer ... communities" (Ostrom et al., 2010, p. 22). Empirical research on participation in online communities is scarce (Munzel and Kunz, 2014), and the little that exists often takes a provider perspective on customer participation and contribution (Fliess et al., 2014) or relates only to more specific communities like brand communities (e.g. Hammedi et al., 2015; Martins and Patrício, 2013; Wirtz et al., 2013). By 
identifying and prioritizing the antecedents of participation in IBOCs we offer community providers insights into how to stimulate participation and thereby secure their business.

\section{Theoretical Foundation and Model Overview}

Members of IBOCs connect to exchange information (Wiertz and de Ruyter, 2007). The service provider managing the online community offers the platform for members to do so, but the key element of the service — exchanging information — is delivered by the community members themselves (Kozinets et al., 2010). Participating in an IBOC thus involves providing and receiving information.

Social exchange theory (SET, Blau, 1964; Homans, 1966; Thibaut and Kelley, 1959) can serve as a foundation to explicate interpersonal exchanges in communities (e.g., Munzel and Kunz, 2014). An exchange in marketing involves "a transfer of something tangible or intangible, actual or symbolic between two or more social actors" (Bagozzi, 1979, p. 434), with actors being individuals or groups and organizations (Bagozzi, 1978). In IBOCs information is exchanged among the members as well as with the provider. Exchanges can be evaluated in terms of their outcomes, such as "monetary gains or losses, social rewards (e.g., approval, praise, status) or social punishment (e.g., prejudice, discrimination, ostracism)" (Bagozzi, 1978, p. 538). SET predicts that human actions are motivated by expectations of returns, with these returns reflecting both social and economic elements. Members continue to exchange only if doing so generates value and the expected rewards exceed the expected costs (Blau, 1964; Homans, 1966). Addressing the social elements of exchanges is particularly relevant in IBOCs, because their core offerings are connections among members and the exchange of information. 
In keeping with the prior literature and considering the triad of actors in OCs (provider, focal member, and other members), we define the costs and rewards of member participation according to both intra- and interpersonal influences on the focal member (Dholakia et al., 2004; Rothaermel and Sugiyama, 2001; Zhu et al., 2012). In our model, we include member-specific characteristics, which represent the intrapersonal influence, together with co-member-specific and provider-specific antecedents that reflect the interpersonal influences on these actors (see Figure 1). All three actors are important stakeholders influencing participation and community success (Dholakia et al., 2004; Eisenmann et al., 2006; Hennig-Thurau et al., 2010). This threeactor perspective complements existing research on customer participation in online communities that subdivides antecedents into social and functional drivers (Wirtz et al., 2013) or environmental and individual (Bolton et al., 2013).

\section{Insert Figure 1 about here}

The antecedents for each stakeholder group are deduced from prior customer participation literature. First, in terms of focal member antecedents, we investigate the effect of each member's role clarity and ability (Auh et al., 2007; Guo et al., 2013; Meuter et al., 2005), which are important antecedents of participation (Fliess et al., 2014). Another key condition is customers' incentives to perform specific roles in service processes (Gallan et al., 2013). To represent these incentives, we include an enjoyment variable in our model. Prior literature identifies (expected) enjoyment as a strong incentive to participate in online settings (Dabholkar and Bagozzi, 2002; Dholakia et al., 2009; Etgar, 2008) and uses this variable to operationalize motivation as (expected) enjoyment (Venkatesh et al., 2002). Finally, because the focal member antecedents are unlikely to be independent, we include enjoyment as a moderating variable in some of our model paths. 
Second, each focal member is influenced by his or her virtual encounters with other members in the IBOC (Hennig-Thurau et al., 2010), so we include a co-member antecedent of member participation. Shen et al. (2010) specify that perceived co-member expertise exerts a significant effect on a member's activity. Ridings et al. (2006) also show that community members express more trust in the abilities, integrity, and benevolence of active co-members than inactive ones. Customers evaluate interpersonal qualities during transactions, which determine their perception of interactional justice (Auh et al., 2007). This evaluation combines all the evaluated elements into an overall perception of co-members' cooperation, which we use as the variable representing co-members' antecedent of participation.

Third, in a multi-actor OC context, the evaluation of interpersonal treatment also involves the provider, whose exhibited interactional justice is an antecedent of participation (Auh et al., 2007). Thus the provider antecedent variable acknowledges that the provider supplies the technical interface and defines and monitors rules for exchanges (Porter and Donthu, 2008; Xue and Harker, 2002), so its responsiveness to members' concerns should be key to participation.

\section{Research Hypotheses}

\section{Focal Member Antecedents}

Ability. A member needs certain skills to perform various tasks online (Meuter et al., 2005) and for various services (Moeller et al., 2013). To participate, the member must be familiar with the basic rules of web-based exchanges (e.g., setting up a profile, uploading content, searching for other members, writing messages; Kelley et al., 1990). The skills and knowledge required to participate in web-based exchanges in general define ability. Thus, ability is linked to the general skills and knowledge one must possess to be able to perform a task (Bowen, 1986); it is not necessarily specific to online communities or even a particular online 
community. Ability is knowledge and skills of the possibilities and technicalities of web-based exchanges on an abstract level. Thus ability is distinguished from role clarity, which instead relates to certain processes in a given context, and the expectation others have about the role the customer might play in this community (Bowen, 1986; Guo et al., 2013).

Members with greater ability are more capable of performing certain necessary tasks, and so can leverage the benefits of participation better than members with lesser ability (Thibaut and Kelley, 1959). Ability decreases the costs of participation by lowering the mental and physical effort required (Lengnick-Hall, 1996). Whereas in offline service settings customer activities can be quite substantial and involve physical effort (e.g., travel, physiotherapy, gym class), the effort in other service settings, as in online service settings, will be mostly mental (Moeller et al., 2013). Thus, according to social exchange theory, more skilled members likely engage more efficiently thanks to higher rewards. In contrast, less skilled members perceive higher costs for the same quantity of participation, and they may even refrain if engaging appears too difficult or time consuming (Dabholkar, 1990). They likely fear suboptimal outcomes, which would lower their benefits and increase their costs (Auh et al., 2007). Therefore, following social exchange theory, members with more ability should be more likely to participate in the community.

Rather than a positive, linear relationship, however, we propose a positive, quadratic effect for IBOCs, such that the effects of ability on participation should increase disproportionally at higher levels. Less skilled members may feel overextended if the demands of the IBOC exceed their abilities (Singh, 1998). If the effort seems too high, participation will likely be perceived as very time consuming. Although we can assume a minimum level of ability, given that all members subscribed to the IBOC, those with more ability should reveal disproportionately higher participation, because their perceived benefits increase while their 
costs decrease. They also can profit from learning effects - meaning that as their contributions demand less mental effort, participation may even come to seem routine. Because they contribute more efficiently and have confidence that their participation leads to optimal outcomes, we hypothesize:

$\mathbf{H}_{1}$ : The effect of a member's ability on participation is positive and nonlinear; greater levels of ability increase participation at an increasing rate.

Role clarity. This antecedent refers to customers' understanding and knowledge of the roles that they must perform in any particular service setting (Bowen, 1986; Guo et al., 2013; Meuter et al., 2005). Unlike ability, role clarity refers to knowledge related to a specific IBOC, rather than an abstract form of the knowledge and skills needed to participate in web-based services more generally (Etgar, 2008, Verleye 2015). Thus it entails members' knowledge of the procedures and rules of a specific IBOC as well as an understanding of the tasks required to accomplish an exchange. In turn, role clarity reflects the specific investment, in time and effort, that a member makes to participate in a particular IBOC, which in turn determines participation (Lengnick-Hall, 1996). The extent to which customers understand their roles and know what is expected of them for service delivery enhances their contributions (Bowen, 1986).

SET implies that role clarity increases the perceived benefits and decreases the costs of participation. Three reasons support this relationship in an IBOC context. First, members with greater role clarity should better recognize the benefits they can realize through participation (Bowen, 1986). Second, role clarity reduces uncertainty associated with participation in an IBOC along with the costs of searching for information, which members do to lower their uncertainty. 
Third, a lack of role clarity provokes stress and higher perceived costs (Bowen, 1986), so members with low role clarity may be less willing to participate (Groth, 2005).

Here again we predict that the positive relationship between role clarity and participation is not linear, and instead propose a positive quadratic effect whereby the influence of role clarity grows stronger at higher levels of participation. Members who are not familiar with various participation possibilities might not realize the diverse ways that they can get involved. In addition, the costly information search required to learn the IBOC's functionalities and the psychological costs associated with the stress of uncertainty may outweigh the perceived benefits. As a member increasingly comes to understand the logic of a community, role clarity likewise increases his or her participation disproportionately with each additional unit. Beyond some role clarity threshold, the benefits of participation disproportionately outweigh its costs and should exert a stronger effect. For example, if members learn that an IBOC offers standardized ways to post content, they can save time by using these standardized formats, which makes their participation more efficient. A member with such knowledge can participate and exchange more than a member without that knowledge. Providers can increase a member's role clarity by increasing the usability of an IBOC or ameliorating support options, which should prompt members to reciprocate with higher levels of participation. Thus,

$\mathbf{H}_{2}$ : The effect of a member's role clarity on participation is positive and nonlinear; greater levels of role clarity increase participation at an increasing rate.

Enjoyment. The willingness to participate likely reflects the extent to which members enjoy participation in an IBOC (Davis et al., 1992; Venkatesh et al., 2002). Enjoyment increases members' likelihood of participating in the future (Füller et al., 2009/10), because members who 
have experienced enjoyment in the past likely expect to derive enjoyment from future participation. Therefore, we include expected enjoyment in our model (hereafter, "enjoyment"), defined as the degree to which participation "is perceived to provide reinforcement in its own right, apart from any performance consequences that may be anticipated" (Childers et al., 2001, p. 513). In line with SET and also with prior empirical findings in a technological service provision context, enjoyment is a key determinant of participation (Dabholkar and Bagozzi, 2002). Enjoyment increases the benefits associated with participation and decreases its perceived costs, because members who enjoy participating find value in the process itself and associate higher benefits with it. Bendapudi and Leone (2003) also emphasize that enjoyment increases psychic benefits, meaning that the more members enjoy the service process, the more benefits they gain from the social interaction and the lower their perceived cost. Costs associated with the time spent participating likely seem less salient to members who enjoy that activity. Therefore, we anticipate that enjoyment will have a positive impact on participation:

$\mathbf{H}_{3}$ : A member's enjoyment has a positive effect on participation.

\section{Interaction Effects Among Focal Member Antecedents}

Users who enjoy a technology tend to underestimate its difficulties and find it easier to use (Venkatesh et al., 2002). They appreciate the process of using the technology and perceive their effort as less than users who do not enjoy using it. Similarly, members who enjoy participating on IBOCs should derive more pleasure from the activity and accept higher costs. Even if, as we have argued, a member's ability and role clarity decrease the costs of participation, these two antecedents may be less important at higher levels of enjoyment, which itself might serve as a reward (Homans, 1966). In contrast, if members do not enjoy their 
participation, they likely attach more importance to cost efficiency, and role clarity and ability may have stronger impacts on participation. In turn, the nonlinear relationship we predicted should grow weaker for higher degrees of enjoyment:

$\mathbf{H}_{4}$ : A higher degree of enjoyment weakens the positive quadratic effects of a member's (a) ability and (b) role clarity on participation.

\section{Co-Members' Antecedents}

While participating in IBOCs, focal members encounter co-members that influence their participation behavior (Hennig-Thurau et al., 2010). The focal member's perceptions of comembers' cooperation, or the extent to which they are willing to contribute to the $\mathrm{OC}$, should be another antecedent of participation. If customers perceive the interaction with exchange partners to be fair, they engage in more participation (Auh et al., 2007). In IBOCs, these exchange partners are co-members. Therefore, we predict that co-members' cooperative behavior influences the perceived benefits and costs of participation. If the focal member believes that comembers use and contribute to the IBOC, that perception should increase his or her anticipation of finding balanced reciprocity in this IBOC, which then stimulates participation (Wiertz and de Ruyter, 2007). Perceiving co-members as cooperative should lead the focal member to anticipate a positive net benefit (Arena and Conein, 2008). In contrast, if the focal member believes comembers fail to participate and contribute to the community, he or she likely fears greater costs related to diminished service quality and quantity (Auh et al., 2007). This effort would decrease the likelihood of finding balanced reciprocity. Consequently, focal members might reduce their own scope of participation if they perceive low cooperation among co-members. In line with SET, we propose: 
$\mathbf{H}_{5}$ : Perceived co-member cooperation has a positive effect on participation.

\section{Provider Antecedents}

The provider is the third important actor in the IBOC triad, determining the community's environment, setting the rules of conduct (Rothaermel and Sugiyama, 2001), and enabling exchange among members. Yet the provider might dampen participation by failing to manage the community properly or running an IBOC that is difficult to use (Xue and Harker, 2002). A responsive provider builds and reconfigures the IBOC to correspond to members' needs (Rothaermel and Sugiyama, 2001), beyond simply its IT infrastructure, usability, or site content. The provider takes an active role and deals directly with members' problems or concerns: facilitating atypical interactions, for example, or finding solutions to problems as well as ensuring content quality (Porter and Donthu, 2008; Rothaermel and Sugiyama, 2001). We predict that these activities determine the benefits and costs of a focal member's participation. With greater provider responsiveness, the control costs for each individual member decrease. Moreover, a highly responsive provider that creates a well-managed OC makes transactions easy and efficient, so the member's costs of participation decrease further. In line with SET, members should reciprocate this positive behavior by increasing their own participation; thus we hypothesize:

$\mathbf{H}_{6}$ : Perceived provider responsiveness has a positive effect on participation.

\section{Study 1: Antecedents of Participation in an IBOC}

\section{Study Design and Sample}


For our empirical study, we chose a worldwide known IBOC with a membership base that regularly covers a substantial proportion of the population in each country (up to $50 \%$ ). In line with our definition, the chosen IBOC offers its members the possibility of creating and cultivating relationships by providing and receiving information.

To test our model we surveyed a representative consumer sample of users of an IBOC. A large international market research firm sent out the online questionnaire to their panel members and supported the data collection. The market research firm provided every respondent with a small monetary incentive $(0.70 €)$ in exchange for their participation. The author team checked that the panel provider addressed the general limitations of market research panels (e.g., recruitment bias). Because we needed to ensure that the participants were knowledgeable enough to answer the questions relating to the particular IBOC, we asked the market research firm to collect a representative sample of users of this IBOC. We agreed to define "users" as having an account and being logged in to the IBOC at least once a month.

The initial sample consisted of 368 participants: We excluded two cases from the dataset due to inappropriate answers (e.g., no serious response to open demographic questions). One case was sorted out due to the speed at which the questionnaire was answered. Moreover, we eliminated eight cases due to inactivity in the IBOC. To identify those cases, we used one of our initial questions, asking participants to state how often they had used a specific IBOC activity, chosen from a list of activities, in the last month. Those responding with a "zero" to all those IBOC activities, even to "reading posts," were excluded from analysis. We used the same question to identify seven users who provided implausible answers about their participation behavior. 
The final sample consisted of 350 German participants and was representative for the IBOC's population in terms of gender $(50.6 \%$ men $)$ and age $(22.3 \%$ younger than 20 years, $32 \%$ 20-29 years of age, $21.1 \%$ between $30-39$ years, $14 \% 40-49$ years of age, $6.6 \%$ between $50-59$ years, and $4 \% 60$ years or older). At the time of the survey, the respondents stated that their membership lengths ranged from four months to eight years $(\mathrm{M}=38.88$ months; $\mathrm{SD}=15.96$ months).

\section{Measures}

To measure our constructs, we referred to existing scales and adapted them to the study context (all responses used seven-point, Likert-type scales, from $1=$ "strongly disagree" to 7 = "strongly agree"; see Table 1).

\section{Insert Table 1 about here}

Member's ability was operationalized with a scale adapted from Auh et al. (2007) and Meuter et al. (2005). We measured role clarity with a scale adapted from Köhler et al. (2011) and Meuter et al. (2005). The enjoyment scale was taken from Venkatesh et al. (2002). As deduced in the theoretical foundation, perceptions of co-members' cooperation were measured by the interactional justice scale proposed by Auh et al. (2007) and a scale of benevolence/integrity within virtual communities proposed by Ridings et al. (2006), both modified to refer to co-members' behavior. Finally, the provider's perceived responsiveness was captured with an adapted version of a scale used by Auh et al. (2007). The dependent variable participation was measured with participants' self-reported participation activity, using a scale provided by Gallan et al. (2013).

We ran a confirmatory factor analysis in Mplus 6.1 (Muthén and Muthén, 2010). The measurement model provided a good fit with the data $\left(\chi^{2}(137)=338.64, p=.00 ; \mathrm{CFI}=.96\right.$; 
RMSEA $=.065 ; \mathrm{p}<.05=.00)$. As Table 2 shows, each construct revealed good psychometric properties in terms of CR ( $\geq .88)$ and $\operatorname{AVE}(\geq .65)$, in support of their good internal consistency. Indicating convergent validity (Hulland, 1999), the standardized loadings of the measures on the corresponding construct were equal to or exceeded .70. Moreover, all constructs showed discriminant validity (see Table 3; Fornell and Larcker 1981).

Insert Table 2 about here

\section{Hypotheses Testing}

We used the PLS estimator, implemented in Smart PLS 2.0 M3 (Ringle et al., 2005), to analyze the hypotheses. We constructed the squared and interaction terms by multiplying the mean-centered items of the specific constructs. To test the proposed relationships for statistical significance, we used a bootstrapping procedure with 350 cases and 700 resamples (Ringle et al., 2005). The standardized coefficients of the structural model appear in Table 3.

\section{Insert Table 3 about here}

We applied a hierarchical approach, by first estimating the main effects in the linear model (Table 3, first column, linear model), then adding the quadratic and interaction effects in the final model (Table 3, second column, final model). Community tenure, gender, and age served as the control variables. An incremental F-test (Chin et al., 2003) confirmed that the addition of the quadratic and interaction effects increased the explained variance significantly $\left(\Delta \mathrm{R}^{2}=.042 ; \mathrm{F}(6,335)=4.19, p<.05\right)$. The model explained $43.9 \%$ of the variance in participation of the respondents.

Interestingly, we did not find support for $\mathrm{H}_{1}$, because members' ability did not influence participation significantly. In support of $\mathrm{H}_{2}$, we found evidence of a strong, positive, significant, nonlinear effect of members' role clarity on participation $\left(\beta_{\text {role clarity }^{2}}=.326, p<.01\right)$. Our results 
indicated a positive effect of enjoyment on participation $\left(\beta_{\text {enjoyment }}=.298, p<.1\right)$, in line with $\mathrm{H}_{3}$. Enjoyment also negatively moderated the quadratic effects of member ability $\left(\beta_{\text {ability }^{2} \times \text { enjoyment }=-}\right.$ $.175, p<.05)$ and role clarity $\left(\beta_{\text {role clarity }{ }^{2} \text { enjoyment }}=-.155, p<.1\right)$ on coproduction, which supported $\mathrm{H}_{4 \mathrm{a}}$ and $\mathrm{H}_{4 \mathrm{~b}}$.

Counter to $\mathrm{H}_{5}$, the results indicated a weak and negative relationship between perceived comembers' cooperation and coproduction $\left(\beta_{\text {cooperation }}=-.067, p<.1\right)$. For the co-member and provider antecedents, the findings affirmed a positive effect of the provider's responsiveness $\left(\beta_{\text {responsiveness }}=.295, p<.01\right)$, in support of $\mathrm{H}_{6}$. Comparing the strengths of the different antecedents, we discovered that role clarity explained the greatest share of variance.

\section{Study 2: Result Reflection with OC Experts}

Some of the results in Study 1, in particular the significant negative impact of comembers' cooperation on participation and the non-significant effect of member's ability in IBOCs, are inconsistent with both theory and our hypotheses. One of our contributions is to investigate participation behavior within a triadic relationship, whereas existing participation literature focuses on the dyadic relationship between customers and service providers (e.g., Bendapudi and Leone, 2003; Chan et al., 2010). Triadic social exchanges on the web are structurally different from dyadic exchanges in traditional service situations and can still be considered as a fairly new phenomenon in participation literature. This might explain the divergence between theory and literature. With Study 2, we aimed to investigate whether our results were at least consistent with reality. Thus, in line with the literature in Marketing and related fields (e.g., Roggeveen, Tsiros and Grewal, 2012 and Rosenthal, 1984) we involved experts to reflect on our results in order to enrich the discussion and the managerial implications.

\section{Study Design and Sample}


To get access to online community experts we screened the World Wide Web for listings of OCs and other references to OCs that are common in the country where the study was conducted. With this procedure, we gathered a list of 89 different OCs, then searched for an appropriate email address. We aimed to generate a list of emails for the general management of each OC; since this was not always possible, we also sent emails to non-person specific addresses (e.g., from customer support) with a request to forward it to the management team. We programmed an online questionnaire that was sent to these email addresses by one of the authors. After eight days, we sent a reminder (three participants answered after receiving the reminder). The questionnaire started with an explanation of the purpose of the survey, followed by some questions about the community and demographics of the experts. In the second part, we shared with the experts six different results that emerged from Study 1. Specifically, we asked them to evaluate, on a seven-point scale, whether each result represented reality, from their point of view (1 = "absolutely not," 7 = "absolutely"). We added an answer option that indicated that the expert was unable to make statements to this particular result. In an open-ended question format the experts then explained their opinions, based on their job experience.

We received answers from ten experts ( 7 men; $28-51$ years, $M=38.7$ years, $S D=8.23$ years) who worked for OCs, mainly as general managers but also in marketing and public relations, or R\&D departments (see Table 4). This amounts to a response rate of $11.24 \%$, whereas the response rate is usually lower for high-level managers (Baruch, 1999).

\section{Results}


The OC experts testified that our results effectively represented reality (means ranging from 5.50 to 6.70$)$, with the exception of negative impact of co-members' cooperation $(\mathrm{M}=$ 3.70), as we discuss subsequently. Given the small number of cases $(n=10)$ in the result reflection, these means need to be considered carefully. We put more emphasis on the detailed explanations for the phenomena provided by the experts, which we use to frame our discussion and managerial implications.

\section{Discussion}

We have proposed and tested antecedents of participation in IBOCs that relate to focal members (role clarity, ability, enjoyment), co-members (cooperation), and the provider (perceived responsiveness). To enhance the validity of our analysis, we integrated potential nonlinear effects of the focal member antecedents on participation and included enjoyment as a potential moderator. In Study 2, we reflected some of our results with OC experts. Thus the findings provide a detailed view of the factors that lead IBOC members to participate, with key insights for the service marketing and participation literature and OC management.

We identify three main antecedents of participation in the hypothesized model: role clarity, enjoyment and provider's responsiveness. Of the antecedents we examined, role clarity exerts the strongest effect on participation, growing stronger with greater role clarity. As one of our expert informants explains, “There are many unwritten rules (e.g., kind of greetings, phrases, abbreviations) that are understandable only for insiders and which are used for differentiation from other communities. The most active members are aware of these rules and move within the community as the proverbial fish in water" (R09_M_47). Academic literature supports this. Hammedi et al., (2015) point out that communities have their rituals and traditions and Rothaermel and Sugiyama (2001) argue that OC members tend to participate passively until they 
learn about the functions and intricacies of a specific OC. Once they become comfortable and familiar, members increase their participation (Tsai and Bagozzi, 2014).

In this regard, we found an interesting boundary condition, in that the impact of role clarity becomes stronger at lower levels of enjoyment. If members do not enjoy coproducing, they will not receive immaterial rewards, so they focus more on cost efficiency (Homans 1966). If members enjoy coproducing in an IBOC, they expect to experience this enjoyment in future coproduction, which seems to serve as a reward. One expert (R01_M_31) states: "Whenever I enjoy things I will do them no matter what." In line with SET (e.g., Blau, 1964), the presence of rewards seems to outweigh the costs of lacking role clarity in an IBOC. Prior research on IBOCs support this notion by revealing that social benefits (Dholakia et al., 2009), identification with the community (Bagozzi and Dholakia, 2006; Hammedi et al., 2015), and we-intentions (Dholakia et al., 2004; Tsai and Bagozzi, 2014) constitute important antecedents of member participation.

The potential to engender a feeling of community can also explain why the provider's responsiveness is quite important in IBOCs. As one expert explains, a strong sense of community in IBOCs means that "the contact and the active recognition of the provider of the community as the host is important" (R08_M_35). An IBOC expert (R07_M_46) also notes that in IBOCs, compliance with social norms is guaranteed by the community provider; thus responsiveness is important.

Furthermore, we find no significant effect of members' ability on participation. Ability is often cited as important driver in participation literature (e.g., Auh et al., 2007; Meuter et al., 2005), but this relationship seems absent in IBOCs. We find a significant linear effect of ability in the IBOC linear model (see Table 3), but it vanishes when we include quadratic and 
interaction effects. The OC experts indicated that this result reflects reality $(\mathrm{M}=5.50)$, because the IBOCs are associated with low levels of financial risks. Members do not fear that their lack of ability may have consequences since the risks in IBOCs are more nonmonetary (e.g., social risk, Mitchell, 1998).

These arguments, and the non-existence of a direct effect of ability in IBOCs, are supported by our interaction effect finding. IBOCs members seem not to care much about low ability, but instead focus on the benefits of high enjoyment. In IBOCs, this trade-off between ability and enjoyment may even be the central mechanism, such that ability and a focus on cost efficiency may only have a positive impact on participation when enjoyment is low. One expert (R02_F_51) states that less able members of her community are often more active. Two other OC experts (R06_M_31; R09_M_47) affirmed this reasoning by offering real-world examples of OC members who enjoy participating so much that they engage in greater participation, even though the content they provide lacks quality.

Finally, in contrast to prior research that has emphasized the importance of social components in OCs (Bagozzi and Dholakia, 2006; Dholakia et al., 2009; Mathwick et al., 2008), as well as with our predictions, we found that co-members' cooperation showed a negative effect. Our experts are mixed in their evaluation of whether this result fully reflects reality $(\mathrm{M}=$ 3.70). One explanation from our experts (R10_M_35) for this effect is "lurking," or what has been termed as "peripheral participation" (Yeow, Johnson, and Faraj 2006). If some community members are very active and very cooperative, then other members might feel it is unnecessary to contribute to and cooperate in a similar fashion. Another explanation (R09_M_47) is that members sign up only to have a look but then become inactive, even though other members are very cooperative. 
In regards to the negative effect of cooperation on participation, one of the experts offered a potential explanation: It results from the "fear of not being able to communicate at the right level or contributing content that is perceived by others as unqualified or ridiculous" (R05_M_36). That is, if other members seem highly cooperative, the focal member may face increasing, instead of decreasing, costs of participation owing to the pressure to participate at the same (qualitative) level and guarantee balanced reciprocity. Otherwise, the focal member may worry about suffering reputational losses or receiving complaints from co-members. This result challenges established opinions and former research, but it suggests that social components might have a dark side as well.

These results thus offer a wide range of insights into the antecedents of participation. Role clarity is indisputably the main lever even though enjoyment still represents a meaningful variable influencing participation, especially as a boundary condition that may mitigate the effects of role clarity and ability on participation.

\section{Contributions}

We contribute to service literature in several ways. First, we identify factors that influence the behavior of existing customers - in our context, members of an IBOC. Our findings contribute to a better understanding of how to increase members' participation and thus OC success. Second, we transfer insights from participation literature to a community domain, which surprisingly has not been attempted previously. In so doing, we assess the influence of factors that research has predicted are key to participation in a general service delivery within an OC context (Auh et al., 2007; Guo et al., 2013; Meuter et al., 2005). Third, we enrich participation literature by considering nonlinear effects. To the best of our knowledge, this study is the first to do this. We show that in an online context, it is necessary to account for the nonlinear effects of 
the key drivers of participation, namely role clarity and ability (e.g., Auh et al., 2007; Meuter et $a l ., 2005)$. Failing to do so disguises the disproportionate effects that they exert on participation in IBOCs. Our approach leads to more accurate conclusions for both theory and management. Fourth, we identify boundary conditions that challenge the impact of ability and role clarity as antecedents. Enjoyment has been previously identified as an important hedonic antecedent of customer participation (Dabholkar and Bagozzi, 2002; Yim et al., 2012). By including it also as a moderator, we reveal that enjoyment weakens the effects of (lacking) ability and of (lacking) role clarity. Thus our results highlight the importance of accounting for antecedents that exert direct and linear impacts but also considering their nonlinear and/or indirect effects.

Finally, from a methodological standpoint, we contribute by introducing a fairly uncommon procedure to the service marketing and management literature: what we term "expert result reflection.” By asking OC experts to review our controversial results, we gained valuable insights that increase the external validity of our results and enrich the participation literature. Thus we infused expert opinions and information about their managerial practices into our findings. Normally expert studies are used to contribute new and original data to a study. Involving experts and making them part of the quality assessment of the data that emerged within a project is, to the best of our knowledge, unusual. In Marketing we have seen expert judges involved in the scale development process (e.g., Hardesty and Bearden, 2004) and in the managerial implication section (Roggeveen, Tsiros and Grewal, 2012). We have not, however, seen experts - i.e., managers that regularly deal with the consumer behavior under study_being asked to judge how much the empirical study results match their reality and why. We believe this procedure enhances the relevance of research to the managerial world. Thus, we encourage others scholars to follow the same route and apply the method of "expert result reflection." 


\section{Managerial Implications}

Our results provide meaningful insights into the antecedents of participation in IBOCs, revealing potential means for managers to increase participation, and indirectly contribute to $\mathrm{OC}$ survival and its revenues.

First, because ability does not affect participation in IBOCs, the providers of an IBOC do not need to worry that lacking ability will be a barrier to participation. This also means that IBOC providers can effectively target all potential members alike regardless of their ability level.

Second, members' expectations of the provider's responsiveness seem to be high, and providers' behavior has an impact on participation, likely because of the social risk that predominates in IBOCs, where legal frameworks provide less protection. Therefore, IBOC providers should proactively monitor members' compliance with social norms and lower the social risk by establishing a strong code of conduct. For example, one of our IBOC experts (R06_M_31) explained that the moderators in his community "have extended rights and can edit or even delete posts of other members if our general terms and conditions have been breached." Members need clear signals that the provider will protect them against public insults or reputation loss.

Third, the most effective lever to enhance participation is increasing members' role clarity and thus the community-specific knowledge. The OC provider can encourage a homogeneous, high level of role clarity among members through careful community design, and its design budget should be allocated mainly to features that increase role clarity. One IBOC expert (R09_M_47) concurs: "When we improved our forum navigation, a clear increase in contributions especially by new members was observed. The old [navigation] was easy to use only for insiders, that is, old members." To increase role clarity, the OC might classify members 
according to their experience and designate experts, premium/gold members, or moderators, because such classifications likely enhance role clarity: "[Moderators] help with questions from the community on how to use the platform" (R06_M_31), suggests one of our experts. Establishing a mentoring program within the community might provide a useful, personal support tool for OC newcomers, because senior members "are especially good role models to indicate the need for proactive participation, spell out community values, and explain the elements of effective participation" (Tsai and Bagozzi, 2014, p. 159).

Fourth, our results reveal the effect that enjoyment shows in interaction with other antecedents. Enjoyment mitigates the effect of ability on participation as well as of role clarity. These results can be interpreted as follows: Enjoyment is able to mitigate a member's feelings, on an abstract level, of lacking personal traits (ability). Likewise if the provider creates an environment that leads to feelings of diminished role clarity (as specific knowledge of the role within this community), enjoyment can ameliorate the negative effects.

Fifth, we recommend aiming to enhance enjoyment given its potential mitigating effects and because it is an antecedent. For example, Facebook regularly introduces innovations, which may help explain its long-term success and continued growth (Bonnington, 2014). Despite the positive effects of enjoyment and new features, however, OC providers should bear in mind the trade-off between increasing enjoyment and reducing role clarity. To balance the advantages and disadvantages of new features, the OC provider might offer users the option to personalize their access, such that they can decide which OC features to install when they log in to their accounts. Then OC newcomers would see and use basic functions until they gain more role clarity, even as experts use the whole range of available features. 
Sixth, we found the negative effect of co-member cooperation remarkable and reflected on this result with our experts. OC providers need to realize that cooperative behaviors can exert social pressures, such that members feel obliged to participate at the same (qualitative) level, but fears about their ability to do so may deter them. In response, the OC provider could introduce a user status system to differentiate members according to their OC experience: learners, new members, advanced users, experts, or moderators, for example. By delineating the reasonable expectations of other members, this system might relieve the social pressure on a particular member. This recommendation could combine effectively with the introduction of mentoring programs and greater OC usability to increase focal members' confidence in their skills.

Seventh, our results indicate that all stakeholders can influence the level of participation of any focal member. If a community provider seeks to increase participation, this must be considered. If, say, the effects of co-members are neglected, a provider cannot address the possible negative outcomes of co-members' cooperation. Furthermore, all OC providers should seek to increase participation, given its importance for their long-term existence (Cho and Menor, 2010).

\section{Limitations and Further Research}

Our research design is subject to several limitations. We sought to gain insights into the important antecedents of participation, but additional research is needed to investigate and develop effective community-specific tools to increase these antecedents, particularly for community managers. We differentiated three focal member antecedents, but we considered only one provider and one co-member antecedent. We hope further research investigates the antecedents of these stakeholder groups in more detail. Furthermore, we gathered data at only one point in time, whereas future research might gather longitudinal data as well. 


\section{References}

Arena, R., and Conein, B. (2008), “On Virtual Communities: Individual Motivations, Reciprocity and We-rationality," International Review of Economics, Vol. 55, No. 1, pp. 185208.

Auh, S., Bell, S.J.; McLeod, C. S. and Shih, E. (2007), “Co-Production and Customer Loyalty in Financial Services,” Journal of Retailing, Vol. 83, No. 3, pp. 359-370.

Bagozzi, R.P. (1978), "Marketing as Exchange. A Theory of Transactions in the Marketplace," American Behavioral Scientist, Vol. 21, No. 4, pp. 535-56.

Bagozzi, R. P. (1979), “Toward a Formal Theory of Marketing Exchanges,” in Ferrell, O.C., Brown, S.W. and Lamb Jr. C.W., (Eds.) Conceptual and Theoretical Developments in Marketing, Chicago: AMA, pp. 431-447.

Bagozzi, R. P. and Dholakia, U.M. (2006), “Open Source Software User Communities: A Study of Participation in Linux User Groups," Management Science, Vol. 52, No. 7, pp. 1099-1115.

Bakos, Y. and Katsamakas, E. (2008), “Design and Ownership of Two-Sided Networks: Implications for Internet Platforms," Journal of Management Information Systems, Vol. 25, No. 2, pp. 171-202.

Baruch, Yehuda (1999), Response Rate in Academic Studies-A comparative analysis, Human Relations, Vol. 52, Iss. 4, pp. 421-438.

Bendapudi, N., and Leone, R.P. (2003), "Psychological Implications of Customer Participation in Co-Production," Journal of Marketing, Vol. 67, No. 1, pp. 14-28.

Blau, P.M. (1964), Exchange and Power in Social Life, New York: John Wiley \& Sons. Bonnington, C. (2014), “Facebook’s Greatest Innovations: The First Decade”, available at http://www.wired.com/2014/02/decade-facebooks-innovations, (accessed July 2015). 
Bowen, D.E. (1986), "Managing Customers as Human Resources in Service Organizations," Human Resource Management, Vol. 25, No. 3, pp. 371-383.

Chan, K.W., Yim, C. K. and Lam, S.S.K. (2010), "Is Customer Participation in Value Creation a Double-Edged Sword? Evidence from Professional Financial Services Across Cultures," Journal of Marketing, Vol. 74, Vol. 3, pp. 48-64.

Childers, T.L., Carr, C.L.; Peck, J. and Carson, S. (2001), "Hedonic and Utilitarian Motivations for Online Retail Shopping Behavior,” Journal of Retailing, Vol. 77, No. 4, 511-535.

Chin, W.W, Marcolin, B.L. and Newsted., P.R. (2003), “A Partial Least Squares Latent Variable Modeling Approach for Measuring Interaction Effects: Results from a Monte Carlo Simulation Study and Voice Mail Emotion/Adoption Study," Information Systems Research, Vol. 14, No. 2, pp. 189-217.

Cho, Y.K. and Menor, L.J. (2010), “Toward a Provider-Based View on the Design and Delivery of Quality E-Service Encounters," Journal of Service Research, Vol. 13, No. 1, pp. 83-95.

Crowd Companies (2014), “A Day in Life of the Collaborative Economy,” available at http://bit.ly/ColEcoDay, (accessed July 2015).

Dabholkar, P.A. (1990), “How to Improve Perceived Service Quality by Improving Customer Participation," in Developments in Marketing Science: Proceedings of the Thirteenth Annual Conference of the Academy of Marketing Science, Vol. XIII, B. J. Dunlap, ed. Cullowhee, NC: Academy of Marketing Science, pp. 483-487.

Dabholkar, P.A. and Bagozzi, R.P. (2002), “An Attitudinal Model of Technology-Based SelfService: Moderating Effects of Consumer Traits and Situational Factors," Journal of the Academy of Marketing Science, Vol. 30, No. 1, pp. 184-201. 
Davis, F.D., Bagozzi, R.P. and Warshaw, P.D. (1992), "Extrinsic and Intrinsic Motivation to Use Computers in the Workplace," Journal of Applied Social Psychology, Vol. 22, No. 14, 111132.

Dholakia, U.M., Bagozzi, R.P. and Pearo, L.K. (2004), “A Social Influence Model of Consumer Participation in Network- and Small-Group-Based Virtual Communities," International Journal of Research in Marketing, Vol. 21, No. 3, pp. 241-263.

Dholakia, U.M., Blazevic, V.; Wiertz, C. and Algesheimer, R. (2009), “Communal Service Delivery: How Customers Benefit From Participation in Firm-Hosted Virtual P3 Communities," Journal of Service Research, Vol. 12, No. 2, pp. 208-226.

Etgar, M. (2008), “A Descriptive Model of the Consumer Co-Production Process,” Journal of the Academy of Marketing Science, Vol. 36, No. 1, pp. 97-108.

Evans, D.S., and Schmalensee, R. (2008), “Markets with Two-Sided Platforms," Issues in Competition Law and Policy, Vol. 1, No. 28, 667-693.

Faraj, S. and Johnson, S.L. (2011), "Network Exchange Patterns in Online Communities," Organization Science, Vol. 22, No. 6, pp. 1464-80.

Fliess, S., Dyck, S. and Schmelter, M. (2014), "Mirror, mirror on the wall - how customers perceive their contribution to service provision", Journal of Service Management, Vol. 25, No. 4, pp. 433-469.

Forbes (2012), Are Brands Wielding More Influence In Social Media Than We Thought? available at http://onforb.es/KOpAQ3, (accessed October 2014).

Fornell, D., and Larcker, D. F. (1981), "Evaluating structural equation models with unobservable variables and measurement error", Journal of Marketing Research, Vol. 18, No. 1, pp. 3950. 
Füller, J., Mühlbacher, H., Matzler, K., and Jawecki, G. (2009/10), “Consumer Empowerment Through Internet-Based Co-creation,” Journal of Management Information Systems, Vol. 26, No. 3, pp. 71-102.

Gallan, A.S., Jarvis, C.B., Brown, S.W., and Bitner, M.J. (2013), "Customer Positivity and Participation in Services: An Empirical Test in a Health Care Context," Journal of the Academy of Marketing Science, Vol. 41, No. 3, pp. 338-356.

Groth, M. (2005), “Customers as Good Soldiers: Examining Citizenship Behaviors in Internet Service Deliveries," Journal of Management, Vol. 31, No. 1, pp. 7-27.

Guo, L., Arnould, E.J., Gruen, T.W., and Tang, C. (2013), “Socializing to Co-Produce: Pathways to Consumers' Financial Well-Being," Journal of Service Research, Vol. 16, No. 4, pp. 549563.

Hammedi, W., Kandampully, J., Zhang, T.T., Bouquiaux, L. (2015), "Online customer engagement: Creating social environments through brand community constellations," Journal of Service Management, Vol. 26, No. 5, pp. 777-806.

Hennig-Thurau, T., Malthouse, E.C., Friege, C., Gensler, S., Lobschat, L., Rangaswamy, A., and Skiera, B. (2010), “The Impact of New Media on Customer Relationships," Journal of Service Research, Vol. 13, No. 3, pp. 311-330.

Homans, G.C. (1966), Social Behaviour: Its Elementary Forms. New York: Harcourt, Brace \& World.

Hulland, J. (1999), “Use of Partial Least Squares (PLS) in Strategic Management Research: A Review of Four Recent Studies," Strategic Management Journal, Vol. 20, No. 2, pp. 195-204. 
Kelley, S.W., Donnelly, J.H. and Skinner, S.J. (1990), ”Conceptualizing Customer Participation in Service Production and Delivery," Journal of Retailing, Vol. 66, No. 3, pp. 315-335.

Khazan, O. (2011), "Facebook Commerce Startups Get in on Gift-buying Season," available at http://www.washingtonpost.com/business/on-small-business/facebook-commerce-startupsget-in-on-gift-buying-season/2011/12/02/gIQAoiP6KO_story.html, (accessed October 8, 2014).

Köhler, C.F., Rohm, A.J., de Ruyter, K. and Wetzels, M. (2011), "Return on Interactivity: The Impact of Online Agents on Newcomer Adjustment," Journal of Marketing, Vol. 75, No. 1, pp. 93-108.

Kozinets, R.V., de Valck, K., Wojnicki, A.C. and Wilner, S.J.S. (2010), "Networked Narratives: Understanding Word-of-Mouth Marketing in Online Communities," Journal of Marketing, Vol. 74, No. 2, pp. 71-89.

Lengnick-Hall, C.A. (1996), “Customer Contributions to Quality: A Different View of the Customer-Oriented Firm," Academy of Management Review, Vol. 21, No. 3, pp. 791-824.

Martins, C.S. and Patrício, L. (2013), "Understanding participation in company social networks", Journal of Service Management, Vol. 24, No. 5, pp. 567-587.

Mathwick, C., Wiertz, C. and de Ruyter, K. (2008), "Social Capital Production in a Virtual P3 Community," Journal of Consumer Research, Vol. 34, No. 6, pp. 832-849.

Meuter, M.L., Bitner, M.J., Ostrom, A.L. and Brown, S.W. (2005), “Choosing Among Alternative Service Delivery Modes: An Investigation of Customer Trial of Self-Service Technologies," Journal of Marketing, Vol. 69, No. 2, pp. 61-83.

Mitchell, V.-W. (1998), Consumer Perceived Risk: Conceptualisations and Models, European Journal of Marketing, Vol. 33, No. 1/2, pp. 163-195. 
Moeller, S. (2010), “Customer Integration-A Key to an Implementation Perspective of Service Provision”, Journal of Service Research, Vol. 11, No. 2, pp. 197-210.

Moeller, S., Ciuchita, R., Mahr, D., Oderkerken-Schroeder, G., Fassnacht, M. (2013), "Uncovering Collaborative Value Creation Patterns and establishing corresponding Customer Roles”, Journal of Service Research, Vol. 16, No. 4, pp. 471-487.

Munzel, A., Kunz, W.H. (2014), "Creators, multipliers, and lurkers: who contributes and who benefits at online review sites", Journal of Service Management, Vol. 25, No. 1, pp. 49-74.

Muthén, L.K. and Muthén, B.O. (2010), Mplus User's Guide. Los Angeles, CA: Muthén \& Muthén.

Ostrom, A.L., Bitner, M.J., Brown, S.W., Burkhard, K.A., Goul, M., Smith-Daniels, V., Demirkan, H., and Rabinovich, E., (2010), “Moving Forward and Making a Difference: Research Priorities for the Science of Service," Journal of Service Research, Vol. 13, No. 1, pp. 4-36.

Porter, C.E. and Donthu, N. (2008), "Cultivating Trust and Harvesting Value in Virtual Communities," Management Science, Vol. 54, No. 1, pp. 113-128.

Ren, Y, Harper, F.M., Drenner, S., Terveen, L., Kiesler, S., Riedl, J. and Kraut, R.E. (2012), "Building Member Attachment in Online Communities: Applying Theories of Group Identity and Interpersonal Bonds," MIS Quarterly, Vol. 36, No. 3, pp. 841-864.

Ridings, C., Gefen, D. and Arinze, B. (2006), "Psychological Barriers: Lurker and Poster Motivation and Behavior in Online Communities," Communications of AIS, Vol. 18, Article 16 , pp. 329-354.

Ringle, C.M., Wende, S. and Will, A. (2005), SmartPLS, www.smartpls.de. 
Roggeveen, A.L., Tsiros, M. and D. Grewal (2012), "Understanding the co-creation effect: when does collaborating with customers provide a lift to service recovery?" Journal of the Academy of Marketing Science, Vol. 40, Iss. 6, pp. 771-790.

Rosenthal, S. R. (1984), "Progress Toward the 'Factory of Future"” Journal of Operations Management, Vol. 4, Iss. 3, pp. 203-229.

Rothaermel, F.T., and Sugiyama, S. (2001), "Virtual Internet Communities and Commercial Success: Individual and Community-Level Theory Grounded in the Atypical Case of TimeZone.com,” Journal of Management, Vol. 27, No. 3, pp. 297-312.

Shen, Y.-C., Huang, C.-Y., Chu, C.-H. and Liao, H.-C. (2010), "Virtual Community Loyalty: An Interpersonal-Interaction Perspective," International Journal of Electronic Commerce, Vol. 15, No. 1, pp. 49-74.

Singh, J. (1998), "Striking a Balance in Boundary-Spanning Positions: An Investigation of Some Unconventional Influences of Role Stressors and Job Characteristics on Job Outcomes of Salespeople," Journal of Marketing, Vol. 62, No. 3, pp. 69-86.

Thibaut, J.W., and Kelley, H.H. (1959), The Social Psychology of Groups, Oxford, England: John Wiley \& Sons.

Tsai, H.-T. and Bagozzi, R.P. (2014), “Contribution Behavior in Virtual Communities: Cognitive, Emotional, and Social Influences,” MIS Quarterly, Vol. 38, No. 1, pp. 143-163. Van Doorn, J., Lemon, K.E., Mittal, V., Nab, S., Pick, D., Pirner, P. and Verhoef, P.C. (2010), "Customer engagement behavior: Theoretical foundations and research directions," Journal of Service Research, Vol. 13, No. 3, pp. 253-266. 
Venkatesh, V., Speier, C. and Morris, M.G. (2002), “User Acceptance Enablers in Individual Decision Making About Technology: Toward an Integrated Model," Decision Sciences, Vol. 33, No. 2, pp. 297-316.

Verleye, Katrien (2015), “The co-creation experience from the customer perspective: its measurement and determinants", Journal of Service Management, Vol. 26, No. 2, pp. 321342.

Wiertz, C., and de Ruyter, K. (2007), "Beyond the Call of Duty: Why Customers Contribute to Firm-hosted Commercial Online Communities," Organization Studies, Vol. 28, No. 3, pp. 347-376.

Wirtz, J., Ambtman, A. den, Bloemer, J.M.M., Horváth, C. ; Ramaseshan, B., Klundert, J. van de, Gurdan Canli, Z., Kandampully, J. (2013), Managing brands and customer engagement in online brand communities, Journal of Service Management, Vol. 24, No. 3, pp. 223-244.

Xue, M., and Harker, P.T. (2002), "Customer Efficiency Concept and Its Impact on E-Business Management," Journal of Service Research, Vol. 4, No. 4, pp. 253-67.

Yim, C.K., Chan, K.W. and Lam, S.S.K. (2012), "Do Customers and Employees Enjoy Service Participation? Synergistic Effects of Self- and Other-Efficacy," Journal of Marketing, Vol. 76, No. 6, pp. 121-140.

Yeow, A., Johnson, S. and Faraj, S. (2006), "Lurking: Legitimate or Illegitimate Peripheral Participation?,” ICIS 2006 Proceedings, Milwaulkee, WI, Vol. 62, pp. 967-982. 
TABLE 1

Measures and Descriptive Statistics

\begin{tabular}{|c|c|c|c|c|c|}
\hline Indicators & $\begin{array}{c}\text { Factor } \\
\text { Loadings }\end{array}$ & $\overline{\text { AVE }}$ & $\alpha^{a}$ & $\overline{C R}$ & $\begin{array}{c}\text { Mean } \\
\text { (SE) }\end{array}$ \\
\hline $\begin{array}{l}\text { Member's role clarity (Köhler et al., 2011; Meuter et al., 2005) } \\
\text { I am well informed about how [community] work/s. } \\
\text { I have knowledge of the advantages and disadvantages of using [community]. } \\
\text { I know what is expected of me if I use [community]. } \\
\text { I know all the rules and principles that have to be considered being active in [community]. }\end{array}$ & $\begin{array}{l}.87 \\
.85 \\
.89 \\
.70 \\
\end{array}$ & .69 & .89 & .90 & $\begin{array}{c}5.57 \\
(1.23)\end{array}$ \\
\hline $\begin{array}{l}\text { Member's ability (Auh et al., 2007; Meuter et al., 2005) } \\
\text { I possess good knowledge of the possibilities that [community] can offer. } \\
\text { I am capable of using all technical features of [community] well. }\end{array}$ & $\begin{array}{l}.92 \\
.94 \\
\end{array}$ & .86 & & & $\begin{array}{c}5.17 \\
(1.45)\end{array}$ \\
\hline $\begin{array}{l}\text { Member's enjoyment (Venkatesh et al., 2002) } \\
\text { I find bartering via/activities in [community] to be enjoyable. } \\
\text { I felt very good about my last activities in [community]. } \\
\text { I have fun trading goods via/being active in [community]. }\end{array}$ & $\begin{array}{l}.90 \\
.89 \\
.93 \\
\end{array}$ & .82 & .93 & .93 & $\begin{array}{c}4.86 \\
(1.42)\end{array}$ \\
\hline $\begin{array}{l}\text { Co-members' cooperation (*Auh et al., 2007, **Ridings } \text { et al., 2006) } \\
\text { My exchange partners behave fairly in dealing with me.** } \\
\text { My exchange partners are usually quick in answering on my messages and posts.* } \\
\text { My exchange partners are usually flexible/helpful when dealing with any concerns I have.* }\end{array}$ & $\begin{array}{l}.85 \\
.82 \\
.84\end{array}$ & .70 & .88 & .88 & $\begin{array}{c}5.20 \\
(1.18)\end{array}$ \\
\hline $\begin{array}{l}\text { Provider's responsiveness (Auh et al., 2007) } \\
\text { I can rely upon [community] to find a solution when there is a problem. } \\
\text { [Community] takes seriously any concerns I have. }\end{array}$ & $\begin{array}{l}.94 \\
.90\end{array}$ & .85 & & & $\begin{array}{c}3.67 \\
(1.55)\end{array}$ \\
\hline $\begin{array}{l}\text { Participation for IBOCs (Gallan et al., 2013) } \\
\text { During my visits to [community], I actively shared information with other members. } \\
\text { I try to keep my [community] profile updated. } \\
\text { I made considerable effort to keep myself informed via [community]. } \\
\text { I worked hard to participate regularly on [community]. } \\
\text { I put a lot of effort into being a good [community] member. }\end{array}$ & $\begin{array}{l}.70 \\
.76 \\
.85 \\
.90 \\
.80\end{array}$ & .65 & .90 & .90 & $\begin{array}{c}4.06 \\
(1.48)\end{array}$ \\
\hline
\end{tabular}

I put a lot of effort into being a good [community] member.

a " $\alpha$ " refers to Cronbachs'alpha. 
TABLE 2

Discriminant Validity Assessment

\begin{tabular}{|c|c|c|c|c|c|c|c|c|c|c|c|c|c|c|c|}
\hline & 1 & 2 & 3 & 4 & 5 & 6 & 7 & 8 & 9 & 10 & 11 & 12 & 13 & 14 & 15 \\
\hline 1 Member's role clarity & .69 & & & & & & & & & & & & & & \\
\hline 2 (Member's role clarity) ${ }^{2}$ & .46 & & & & & & & & & & & & & & \\
\hline 3 Member's ability & .59 & .25 & .86 & & & & & & & & & & & & \\
\hline 4 (Member's ability) $^{2}$ & .27 & .54 & .20 & - & & & & & & & & & & & \\
\hline 5 Member's enjoyment & .16 & .12 & .12 & .10 & .82 & & & & & & & & & & \\
\hline 6 Enjoyment $\times$ Member's role clarity & .53 & .23 & .35 & .16 & .81 & - & & & & & & & & & \\
\hline 7 Enjoyment $\times(\text { Member's role clarity })^{2}$ & .31 & .61 & .14 & .27 & .02 & .10 & - & & & & & & & & \\
\hline 8 Enjoyment $\times$ Member's ability & .43 & .17 & .60 & .15 & .69 & .85 & .07 & - & & & & & & & \\
\hline 9 Enjoyment $\times$ (Member's ability $)^{2}$ & .10 & .32 & .09 & .77 & .00 & .01 & .23 & .01 & - & & & & & & \\
\hline 10 Co-members' cooperation & .24 & .24 & .23 & .18 & .26 & .33 & .15 & .32 & .06 & .70 & & & & & \\
\hline 11 Provider's responsiveness & .04 & .04 & .06 & .01 & .19 & .17 & .01 & .19 & .00 & .08 & .85 & & & & \\
\hline 12 Participation & .07 & .02 & .10 & .05 & .30 & .28 & .01 & .31 & .01 & .08 & .23 & .65 & & & \\
\hline 13 Community tenure & .00 & .00 & .01 & .00 & .00 & .00 & .00 & .00 & .01 & .00 & .00 & .00 & - & & \\
\hline 14 Age & .00 & .00 & .02 & .00 & .00 & .00 & .00 & .00 & .00 & .00 & .00 & .00 & .00 & - & \\
\hline 15 Gender & .00 & .02 & .00 & .01 & .02 & .02 & .02 & .00 & .01 & .02 & .01 & .00 & .00 & .00 & - \\
\hline
\end{tabular}

Notes: Bold numbers on the diagonal indicate the average variance extracted; numbers on the off-diagonal represent the squared correlation. 
TABLE 3

Effects of Participation Antecedents

\begin{tabular}{|c|c|c|c|c|}
\hline \multirow[t]{2}{*}{ Path Tested } & \multicolumn{2}{|c|}{ Standardized Path Coefficients $\beta$} & \multicolumn{2}{|c|}{ Result of hypotheses testing } \\
\hline & Linear Model & Final Model & & \\
\hline Member's ability & $.205^{* * *}$ & $-.073^{\text {n.s. }}$ & & \\
\hline Member's ability ${ }^{2}$ & & $-.027^{\text {n.s. }}$ & $\mathrm{H}_{1}$ : & Not supported \\
\hline Member's role clarity & $-.079^{\text {n.s. }}$ & $.065^{\text {n.s. }}$ & & \\
\hline Member's role clarity ${ }^{2}$ & & $.326^{* * *}$ & $\mathrm{H}_{2}$ : & Supported \\
\hline Member's enjoyment & $.427^{* * *}$ & $.298^{*}$ & $\mathrm{H}_{3}$ : & Supported \\
\hline Co-members' cooperation & $-.069^{\text {n.s. }}$ & $-.067 *$ & $\mathrm{H}_{5}$ : & Not supported \\
\hline Provider's responsiveness & $.280^{* * *}$ & $.295^{* * *}$ & $\mathrm{H}_{6}:$ & Supported \\
\hline Member's ability $\times$ Enjoyment & & $.433^{*}$ & & \\
\hline Member's ability ${ }^{2} \times$ Enjoyment & & $-.175^{* *}$ & $\mathrm{H}_{4 \mathrm{a}}$ : & Supported \\
\hline Member's role clarity $\times$ Enjoyment & & $-.140^{\text {n.s. }}$ & & \\
\hline Member's role clarity $^{2} \times$ Enjoyment & & $-.155^{*}$ & $\mathrm{H}_{4 \mathrm{~b}}$ : & Supported \\
\hline \multicolumn{5}{|l|}{ Control variables: } \\
\hline Community tenure $\rightarrow$ Participation & $.013^{\text {n.s. }}$ & $-.025^{\text {n.s. }}$ & & \\
\hline Age $\rightarrow$ Participation & $.068^{*}$ & $.084^{* * *}$ & & \\
\hline Gender $\rightarrow$ Participation & $.056^{*}$ & $.057^{* *}$ & & \\
\hline
\end{tabular}

${ }^{*} p<.1{ }^{* *} p<.05 .{ }^{* * *} p<.01$. 


\section{TABLE 4}

Participants in the Expert Survey

\begin{tabular}{lcccc}
\hline ID & Type of & Gender & Age & Position \\
& Community & & & \\
\hline R01_M_31 & employees & male & 31 & PR-Manager \\
R02_F_51 & Q\&A community & female & 51 & CEO \\
R03_F_28 & social & female & 28 & PR-Manager \\
R04_F_47 & Q\&A community & female & 47 & - Head of R\&D \\
R05_M_36 & outdoor/tourism & male & 36 & Marketing \\
R06_M_31 & books & male & 31 & CEO \\
R07_M_46 & Q\&A community & male & 46 & CEO \\
R08_M_35 & sharing products & male & 35 & CEO \\
R09_M_47 & photographers & male & 47 & 35 \\
R10_M_35 & sharing products & male & & \\
\hline
\end{tabular}

Note: Two respondents did not offer any information on their current position. 
FIGURE 1

\section{Conceptual Model of Participation Antecedents}

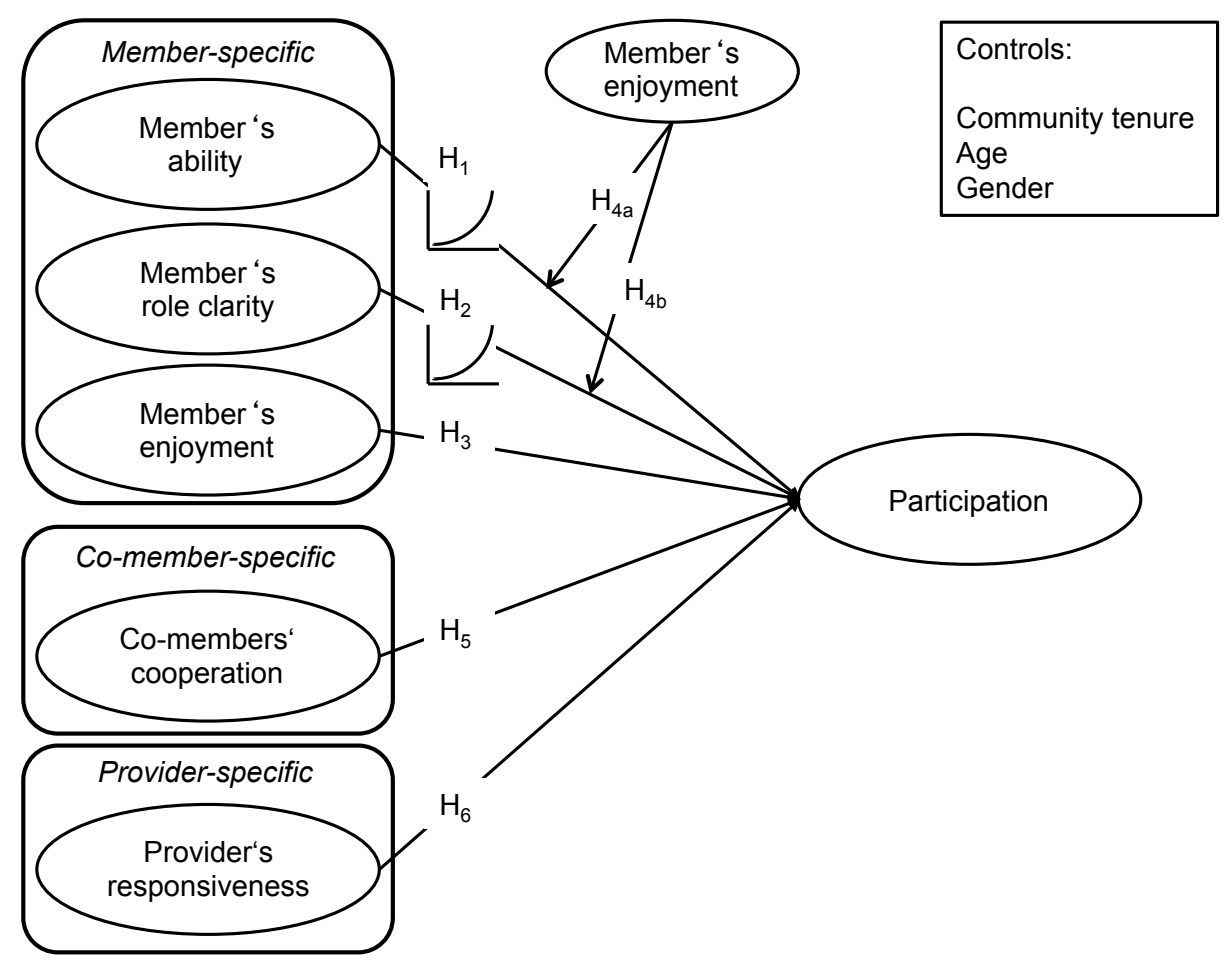

